\title{
ACTIVATING THE FACIAL MUSCLES
}

Visitors to the British Dental Conference and Exhibition will have an opportunity to speak directly to Dr Nick Mohindra, inventor of the innovative Oralift facial rejuvenation device, on stand C30 throughout the show.

The Oralift device is designed to reduce and delay the signs of facial ageing (crow's feet, wrinkles, loss of skin tone, sagging jowls etc) without the need for surgery, needles or artificial fillers.

Oralift is a thermoplastic biteguard which is easy to fit over the mandibular teeth, similarly to a small mouthguard. It is worn for between 30 minutes and two hours, every third day for four months initially. After this, two month top-ups twice a year is all that is needed. Requiring no exercise programme, the facial muscles are simply activated to create the rejuvenating effect by just wearing it in the mouth. After a matter of weeks, patients will start to notice Oralift's rejuvenating effects, which can become stronger and more pronounced as they continue the therapy.

Oralift therapy is simple, easy to use and above all totally natural.

Alternatively you can learn more about the Practice Building Benefits of Oralift by attending one of Nick's Two Day Hands On Courses. The $£ 650$ course fee includes 12 hours of verifiable CPD and a free set of Oralift appliances valued at $£ 180$. The next courses will be held in London on the following dates: 4-5 April and 27-28 June 2014.

For further information or to book a place email info@dentalfacelift.com or visit www.oralift.com.

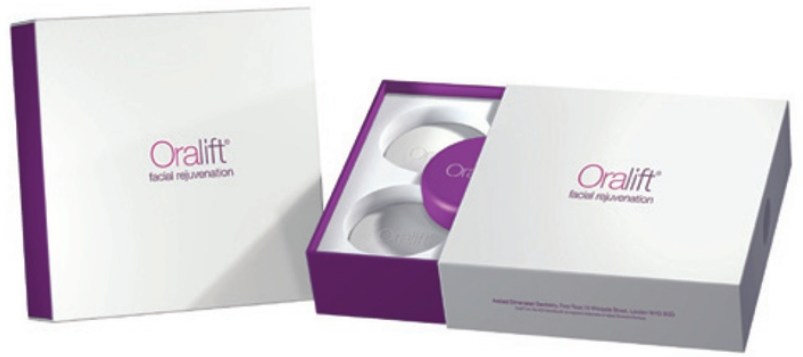

\section{DISCOVER THE TOP PANORAMIC IMAGING SYSTEM}

Demonstrating its award-winning range of digital imaging systems and practice management software, ensure you don't miss Carestream Dental at the British Dental Conference and Exhibition 2014.

Renowned for cutting-edge technologies and first class customer service, Carestream Dental will be on hand to show how you could streamline your practice processes with the R4 Clinical+ practice management software; enhance patient consent with the eSignatures module; or provide a more flexible patient service with CS Solutions, which will be on display both on the stand and within the Innovation Zone on the trade floor.

You can also discover the innovative CS 8100 OPG Unit, which was recently voted the 'Top Panoramic Imaging System of 2014' by The Dental Advisor, with a 99\% rating and an Excellent Five Plus designation.

What's more, the team will be displaying the brand new CS 8100 3D, which delivers high quality 3D images for everyday practice use through compact and easyto-use technology.

To find out more, visit Carestream Dental on stand B21 at the BDA Conference and Exhibition 2014. For more information, contact Carestream Dental on 08001699692 or visit www. carestreamdental.co.uk.

\section{ADVANCE YOUR CAREER AND WIN A HOLIDAY}

If you are looking to develop your clinical skills and to take the next step in your career, be sure not to miss Healthcare Learning: Smileon at this year's British Dental Conference and Exhibition.

The team will be on stand A20 to introduce you to the wide range of qualifications and learning opportunities available:

- The MSc in Restorative \& Aesthetic Dentistry

- DNEZ offering everything from a Dental Nursing Diploma to CPD and job vacancies

- The MBA in Healthcare

- The new MSc in Endodontics

- CORE CPD

- Key Skills III, provided in conjunction with the FGDP.

Find out how you can stay up-to-date with the

\section{AN ARRAY OF FIRST CLASS RESTORATIONS AND SERVICES}

The British Dental Conference and Exhibition 2014 at Manchester Central Convention Complex will present a great opportunity for you to find out just what Sparkle Dental Labs can do for you.

Recently awarded 'Best NHS Laboratory' at the Annual Laboratory Awards 2013, Sparkle Dental Labs offers an array of first class dental restorations and expert services for both NHS and private practices.

The team of more than 50 dental technicians can deliver everything from implants to milled zirconia, chrome cobalt frames and flexible dentures at highly competitive prices and with fast turnaround times.

Sparkle Dental Labs will be on hand at the British Dental Conference and Exhibition to provide any information or advice you may need, particularly with regards to the free pick-up and delivery service available and the full certification provided for every restoration created.

Find out why the awardwinning Sparkle Dental Labs should be your laboratory partner of choice on stand B28 in Manchester.

For any additional information just telephone 0800138 or visit the website, www. sparkledentallabs.com.
Smile-on News family: the App, the Newsletter and Smile-on News. Or sign up for the webinars for free, and discover how you can learn from the best in the business in the comfort of your own home.

With the chance to win a mini holiday on top of all this, make sure you visit Healthcare Learning: Smile-on on stand A20. 